\title{
A Novel WT1 Mutation Identified in a 46,XX Testicular/ Ovotesticular DSD Patient Results in the Retention of Intron 9
}

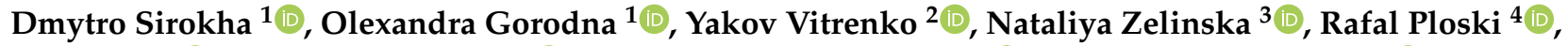

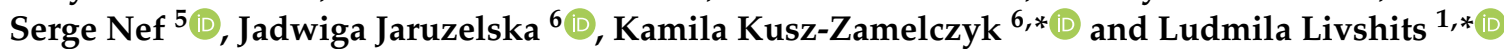

1 Institute of Molecular Biology and Genetics, National Academy of Sciences of Ukraine, 03143 Kyiv, Ukraine; d.a.sirokha@imbg.org.ua (D.S.); a.v.gorodna@imbg.org.ua (O.G.)

2 IMG-Integrated Medical Group, 6K Mykil'ska-Slobids'ka St., 02002 Kyiv, Ukraine; vitrenko@im-group.com.ua

3 Ukrainian Scientific and Practical Center for Endocrine Surgery, Transplantation of Endocrine Organs and Tissues, Ministry of Health of Ukraine, 01021 Kyiv, Ukraine; znb@ukr.net

4 Department of Medical Genetics, Warsaw Medical University, 02-106 Warsaw, Poland; rploski@wp.pl

5 Department of Genetic Medicine and Development, Faculty of Medicine, University of Geneva, 1211 Geneva, Switzerland; Serge.Nef@unige.ch

6 Institute of Human Genetics, Polish Academy of Sciences, 60-479 Poznan, Poland; jadwiga.jaruzelska@igcz.poznan.pl

* Correspondence: kamila.kusz-zamelczyk@igcz.poznan.pl (K.K.-Z.); livshits@edu.imbg.org.ua (L.L.)

check for updates

Citation: Sirokha, D.; Gorodna, O.; Vitrenko, Y.; Zelinska, N.; Ploski, R.; Nef, S.; Jaruzelska, J.; Kusz-

Zamelczyk, K.; Livshits, L. A Novel WT1 Mutation Identified in a 46,XX Testicular/Ovotesticular DSD Patient Results in the Retention of Intron 9. Biology 2021, 10, 1248. https:// doi.org/10.3390/biology10121248

Academic Editor: Hiromitsu Tanaka

Received: 9 November 2021

Accepted: 27 November 2021

Published: 30 November 2021

Publisher's Note: MDPI stays neutral with regard to jurisdictional claims in published maps and institutional affiliations.

Copyright: (c) 2021 by the authors. Licensee MDPI, Basel, Switzerland. This article is an open access article distributed under the terms and conditions of the Creative Commons Attribution (CC BY) license (https:/ / creativecommons.org/licenses/by/ $4.0 /)$.
Simple Summary: Disorders/differences of sexual development are very diverse. Among them is a condition characterized by the presence of testicular tissue in people with female chromosomes, which is typically manifested by male or ambiguous genitalia. While genetic counseling is beneficial for these people and their families, the genetic causes of these cases are only partially understood. We describe a new mutation in the WT1 gene that results in the presence of testicular tissue in a child with a female karyotype. We propose molecular mechanisms disrupted by this mutation. This finding widened our understanding of processes that govern sexual development and can be used to develop diagnostic tests for disorders/differences of sexual development.

Abstract: The 46,XX testicular DSD (disorder/difference of sexual development) and 46,XX ovotesticular DSD (46,XX TDSD and 46,XX OTDSD) phenotypes are caused by genetic rearrangements or point mutations resulting in imbalance between components of the two antagonistic, pro-testicular and pro-ovarian pathways; however, the genetic causes of 46,XX TDSD/OTDSD are not fully understood, and molecular diagnosis for many patients with the conditions is unavailable. Only recently few mutations in the WT1 (WT1 transcription factor; 11p13) gene were described in a group of $46, \mathrm{XX}$ TDSD and 46,XX OTDSD individuals. The WT1 protein contains a DNA/RNA binding domain consisting of four zinc fingers (ZnF) and a three-amino acid (KTS) motif that is present or absent, as a result of alternative splicing, between $\mathrm{ZnF} 3$ and $\mathrm{ZnF} 4$ ( $\pm \mathrm{KTS}$ isoforms). Here, we present a patient with 46,XX TDSD/OTDSD in whom whole exome sequencing revealed a heterozygous de novo WT1 c.1437A>G mutation within an alternative donor splice site which is used for -KTS WT1 isoform formation. So far, no mutation in this splice site has been identified in any patient group. We demonstrated that the mutation results in the retention of intron 9 in the mature mRNA of the $46, X X$ TDSD/OTDSD patient. In cases when the erroneous mRNA is translated, exclusively the expression of a truncated WT1 +KTS protein lacking ZnF4 and no - KTS protein occurs from the mutated allele of the patient. We discuss potential mechanisms and pathways which can be disturbed upon two conditions: Absence of Zn4F and altered +KTS/ - KTS ratio.

Keywords: disorder/difference of sexual development (DSD); testicular DSD (TDSD); ovotesticular DSD (OTDSD); WT1 gene; Wilms' tumor 1 protein; splice site mutation; zinc finger; KTS 


\section{Introduction}

The primary events of gonadal sex determination are genetically controlled in mammals. Distinct pathways lead to the development of testes or ovaries. The pro-testicular pathway is triggered by the $S R Y$ (sex-determining region $Y$ ) gene located on chromosome Yp11.2. In the absence of $S R Y$, the pro-ovarian WNT4/RSPO1 (R-spondin 1) and Catenin beta 1 pathways are activated [1,2]. Male and female genetic programs compete and repress each other. An imbalance between the specific components of these antagonistic pathways results in disorders/differences of sex development (DSD).

DSD are congenital conditions in which chromosomal, gonadal or anatomical sex is atypical [3]. The variety of DSD phenotypes reflects a complexity of genetic networks of sex determination and maintenance. Among them there are 46,XX testicular DSD (TDSD) and ovotesticular DSD (OTDSD), two DSD phenotypes distinguished by the presence of testicular tissue despite a female 46,XX karyotype (MIM 400045). Males with 46,XX TDSD typically have small azoospermic testes [4]. In turn, 46,XX OTDSD refers to individuals who have both ovarian and testicular tissue in their gonads. Their genitalia are usually ambiguous, with the degree of masculinization proportional to the amount of testicular tissue [5].

The most common cause of 46,XX TDSD/OTDSD is the translocation of SRY to chromosome X. In turn, genetic causes of the $S R Y$-negative 46,XX TDSD/OTDSD are variable. Among them, there are chromosomal rearrangements that result in the upregulation of SRY-related HMG-box genes SOX3 (Xq27.1), SOX9 (17q24.3) and SOX10 (22q13.1) which are able to trigger testicular differentiation when their levels are sufficiently increased [6-9]. There are also loss of function mutations of pro-ovarian signalling pathway RSPO1 (1p34.3) and WNT4 (1p36.12) genes [10,11]. More recently, several mutations in the zinc finger 4 (ZnF4) domain of the WT1 gene have been identified in a group of 46,XX TDSD/OTDSD individuals [12,13], but still genetic causes of 46,XX TDSD/OTDSD are not fully understood and molecular diagnosis for many patients with the conditions is unavailable.

The WT1 gene plays an essential role in the normal development of the urogenital system [14]. Protein isoforms encoded by WT1 contain a DNA/RNA binding domain consisting of four zinc fingers (ZnF) and a motif of three amino acids (KTS) present or absent between the $\mathrm{ZnF3}$ and the $\mathrm{ZnF} 4$ ( \pm KTS isoforms). The presence or absence of KTS is an effect of an alternative splicing which is conserved in all vertebrates, suggesting that + KTS and -KTS are functionally distinct [15]. Indeed, both isoforms differ in affinity to DNA/RNA, with - KTS having a higher affinity to DNA, while +KTS binds preferentially to RNA $[16,17]$. The $+\mathrm{KTS}$ is expected to function in splicing and regulating stability of mRNA [17-19]. Isoforms +KTS and - KTS bind to different DNA sequence motifs as well as to different regions of target genes, resulting in a diverse influence on transcription. While the -KTS isoform preferentially binds close to transcription start site as well as to enhancers, thus being related predominately to transcriptional activation, + KTS binds mostly within gene bodies and is related to both activation and repression [20]. Since + KTS and -KTS bind largely to the same genes [20,21] and are able to dimerize [22], it is expected that + KTS and - KTS could cooperate in transcriptional repression.

Distinct roles of each isoform (+KTS and -KTS) in gonadal development were shown in the mouse model. Namely, it was demonstrated that +KTS is essential for testicular determination (it activates $S R Y$ and SOX9), while it represses ovarian development (it downregulates a pro-ovarian NROB1-nuclear receptor subfamily 0 group B member 1 gene; Xp21.2). On the other hand $-\mathrm{KTS}$ is needed for both male and female gonadal development [23]. The proper ratio between those two functionally different +KTS and -KTS WT1 isoforms seems to be critical for correct sexual development since a heterozygous mutation disrupting one alternative splice site and resulting in lower +KTS level causes Frasier syndrome (MIM 136680), characterized among other features by 46,XY gonadal dysgenesis [24,25].

We report a 46,XX TDSD/OTDSD patient who has a novel de novo heterozygous WT1 gene mutation (WT1:c.1437A $>\mathrm{G}$ ) within an alternative donor splice site. We showed that 
the mutation results in the retention of intron 9 in the mature mRNA of the patient. Based on the sequence of the aberrant mRNA containing the intron retained, it is to be expected that the mutated allele of the patient expresses exclusively WT1 +KTS protein lacking ZnF4 and no -KTS isoform, and thus the normal +KTS/ - KTS ratio is altered.

\section{Results}

\subsection{6,XX TDSD/OTDSD Case Report}

The patient was registered as a male at birth. His height and weight were normal. At the age of two months the patient was examined due to hypospadias and bilateral cryptorchidism. At the age of 13 months the genitalia were assessed as stage 2 according to the Prader scale. There was a palpated gonad in the right inguinal canal, while no palpated formation was found in the left one. Ultrasound examination revealed a $16.5 \mathrm{~mm} \times 7.5 \mathrm{~mm} \times 9.5 \mathrm{~mm}$ gonad in the right inguinal canal, while neither uterus nor gonad were found in the pelvis. The height was $74 \mathrm{~cm}$ (normal for a girl and $-1 \mathrm{SD}$ for a boy), weight $9.3 \mathrm{~kg}$, normal BMI $16.9 \mathrm{~kg} / \mathrm{m}^{2}$. The next examination was conducted at the age of 14 months. Ultrasound investigation revealed the right gonad to be $9 \mathrm{~mm} \times 3 \mathrm{~mm}$ and the left one $9 \mathrm{~mm} \times 4 \mathrm{~mm}$ in inguinal canals. They could easily move to the abdominal cavity through a wide inguinal ring. Urogenital sinus and fluorocolpos were detected in the projection of the vagina. Magnetic resonance imaging (MRI) of the pelvic organs revealed prostate and phallus in a typical place. A uterus was not detected using both MRI and ultrasound examination. No signs of Wilms' Tumor or renal anomalies were found in the patient.

Hormonal investigation at the age of two months showed that estradiol (E2) was within the normal range for both sexes, luteinizing hormone (LH) was higher than normal for both sexes and follicle-stimulating hormone (FSH) was within the normal range for girls and higher than the norm for boys. Further hormonal tests at the age of 14 months revealed that anti-Müllerian hormone (AMH) level was higher than normal for girls and normal for boys; dihydrotestosterone (DHT), luteinizing hormone (LH) and Follicle-Stimulating Hormone (FSH) were within the normal range for both sexes. 17-hydroxyprogesterone $(17-\mathrm{OHP})$ was at the upper limit of the normal range. Human chorionic gonadotropin (hCG) testosterone stimulation test showed a high response of testosterone indicating presence of Leydig cells in gonad(s) and proper testosterone biosynthesis (Table 1). Cytogenetic studies of the patient showed a 46,XX karyotype without mosaicism and a lack of chromosome Y-specific sequences including SRY gene.

Taking into consideration (1) the male characteristics of sexual development of the patient-absence of uterus, presence of phallus and prostate-(2) the female karyotype, (3) normal level of 17-OHP excluding congenital adrenal hyperplasia, (4) normal-for-boys level of AMH excluding gonadal dysgenesis and (5) the result of the hCG stimulation indicating the presence of testicular tissue, we concluded that the patient suffered from 46,XX TDSD. However 46,XX OTDSD cannot be ruled out because the patient's gonadal tissue was not available for the study, and without histopathological examination, it is impossible to distinguish between the two conditions. Therefore the temporal diagnosis was $46, X X$ TDSD or $46, X X$ OTDSD (46,XX TDSD/OTDSD).

\subsection{Identification of the Heterozygous WT1:c.1437A>G Mutation in the Patient}

We performed whole exome sequencing (WES) of the patient and his parents to search for the genetic determinants of $46, X X$ TDSD/OTDSD. The sequencing manifested the mean coverage $>145 ; 95.3 \%$ of the targets were covered $>30 \times$ and 45,245 SNVs or small indel variants were identified. After filtration by the quality and population frequency, the number of variants affecting the coding sequence was reduced to 467 variants in 451 genes in the proband. Among the 451 genes carrying variation(s), there were seven genes known to be DSD causing or DSD candidates (Table S1) [26-29], namely DHCR7 (7-dehydrocholesterol reductase; 11q13.4), DYNC2H1 (dynein cytoplasmic 2 heavy chain 1; 11q22.3), FREM2 (FRAS1 related extracellular matrix 2; 13q13.3), SPECC1L (sperm antigen 
with calponin homology and coiled-coil domains 1 like; 22q11.23), SPECC1L-ADORA2A (SPECC1L-ADORA2A readthrough; 22q11.23), BBS9 (Bardet-Biedl syndrome 9; 7p14.3) and WT1. However, variants in four genes (DYNC2H1, SPECC1L-ADORA2A, SPECC1L, $B B S 9$ ) were predicted to be of uncertain significance or benign using Meta-SNP (Table S1). For that reason, we did not further consider their influence on the patient's phenotype. The other two variants of DHCR7 and FREM2 genes were predicted to be pathogenic or likely pathogenic, respectively (Table S1). However, the phenotype of the patient did not fit the Smith-Lemli-Opitz syndrome (MIM 270400) or 46,XY Frasier Syndrome (MIM 136680), which are associated with $D H C R 7$ and FREM2, respectively. Moreover, the same variants were also detected in the healthy father or mother. However, we cannot rule out the modifier effect of those variants.

Table 1. Values of free testosterone (fT) baseline and after human chorionic gonadotropin (hCG) stimulation, dihydrotestosterone (DHT), anti-Müllerian hormone (AMH), estradiol (E2), luteinizing hormone (LH), follicle-stimulating hormone (FSH) and 17-hydroxyprogesterone (17-OHP) of the 46,XX TDSD/OTDSD patient.

\begin{tabular}{|c|c|c|c|c|c|}
\hline Hormone, Unit & & Age 2 Months & $\begin{array}{c}\text { Age } 2 \text { Months } \\
\text { Reference Values }\end{array}$ & Age 14 Months & $\begin{array}{l}\text { Age } 14 \text { Months } \\
\text { Reference Values }\end{array}$ \\
\hline \multirow{2}{*}{$\begin{array}{c}\mathrm{fT}, \\
\mathrm{ng} / \mathrm{dL}\end{array}$} & Baseline & & & 0.001 & $\begin{array}{l}\text { o }<0.5 \\
\sigma^{3}<0.5\end{array}$ \\
\hline & $\begin{array}{l}24 \mathrm{~h} \text { after 3-days } \\
\text { hCG stimulation }\end{array}$ & & & 0.321 & \\
\hline $\begin{array}{r}\mathrm{DHT} \\
\mathrm{ng} / \mathrm{dL}\end{array}$ & & & & 1.186 & $\begin{array}{l}q<3 \\
\sigma^{x}<3\end{array}$ \\
\hline $\begin{array}{r}\mathrm{AMH} \\
\mathrm{ng} / \mathrm{mL}\end{array}$ & & & & 10.56 & $\begin{array}{c}\text { †0.17-8.9 } \\
\overbrace{}^{\top} 3.8-159.8\end{array}$ \\
\hline $\begin{array}{c}\text { E2, } \\
\mathrm{pg} / \mathrm{mL}\end{array}$ & & 0.23 & $\begin{array}{l}q<15 \\
\sigma^{7}<15\end{array}$ & & \\
\hline $\begin{array}{c}\mathrm{LH}, \\
\mathrm{mIU} / \mathrm{mL}\end{array}$ & & 11.19 & $\begin{array}{l}+0.02-7.0 \\
\sigma^{2} 0.02-7.0\end{array}$ & $<0.1$ & $\begin{array}{l}\text { †0.02-0.3 } \\
\sigma^{2} 0.02-0.3\end{array}$ \\
\hline $\begin{array}{c}\mathrm{FSH}, \\
\mathrm{mIU} / \mathrm{mL}\end{array}$ & & 6.43 & $\begin{array}{l}+0.24-14.2 \\
\sigma^{\top} 0.16-4.1\end{array}$ & 1.01 & $\begin{array}{l}\text { } 0.3-11.1 \\
\sigma^{\top} 1.0-4.2\end{array}$ \\
\hline 17-OHP, ng/mL & & & & 0.43 & $\begin{array}{l}\text { क0.1-4.0 } \\
\text { o }^{\top} 0.1-4.0\end{array}$ \\
\hline
\end{tabular}

The only variant which drew our attention was a heterozygous transition in the DSD related WT1 gene, NM_024426.6 c.1437 A>G (11:32413528 T/C GRCh37), not detected in the patient's healthy parents. We confirmed the heterozygous status of the WT1:c.1437 A>G in the patient and the wild type status in both parents by Sanger sequencing (Figure 1). Importantly, the WT1:c.1437 A>G variant was not present in any SNV database. We registered the variant in ClinVar as ID: 981464.

2.3. The WT1:c.1437A>G Mutation Results in the Retention of Intron 9, Predicting Premature Translational Termination and Absence of Zinc Finger 4

The WT1:c.1437A>G substitution identified in this study is localized at the end of exon 9 within the consensus sequence of the upstream alternative donor splice site which is normally utilised to produce the -KTS isoform (Figure 2). However, the Human Splicing Finder (HSF) [30] predicts that the substitution affects splicing from both alternative donor splicing sites. Moreover, according to HSF, the WT1:c.1437A>G substitution impairs the recognition by the SRp40 splicing factor 5 which plays a role in constitutive splicing and selection of alternative splice sites [31]. Thus, based on computational predictions, we expected the WT1:c.1437A $>\mathrm{G}$ mutation to result in the retention of intron 9. 


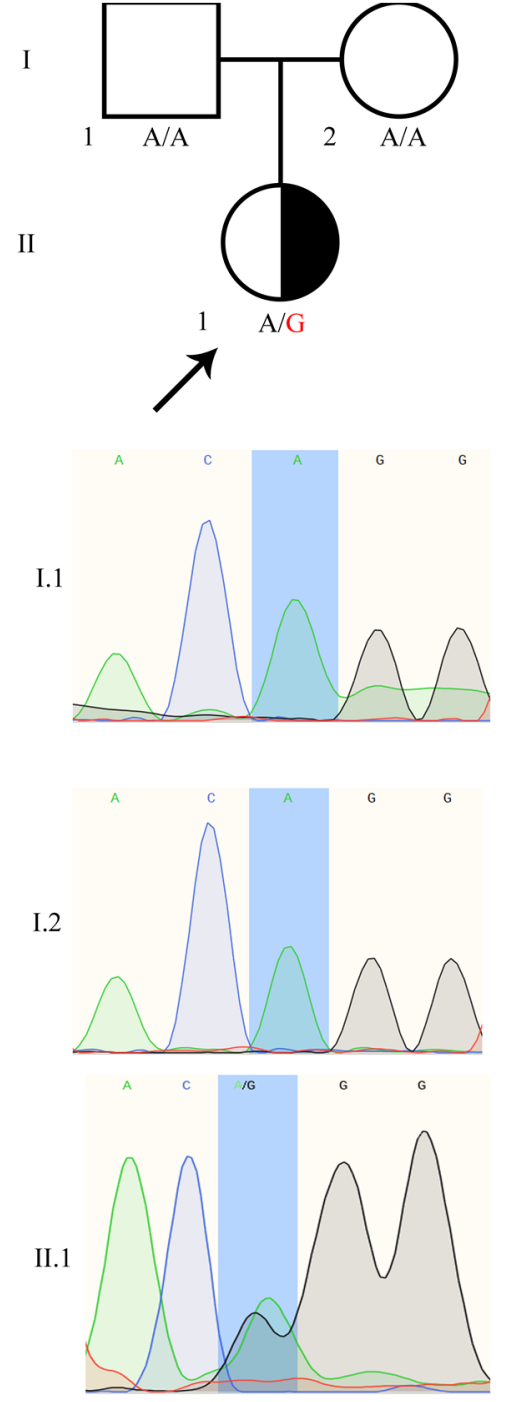

Figure 1. The confirmation of the WT1:c.1437 A>G substitution in the 46,XX TDSD/OTDSD patient. The family member analysis showed de novo occurrence of the mutation in the patient.

The $A>G$ substitution occurs within a donor splicing site used for the formation of the -KTS isoform

The $A>G$ substitution occurs upstream of a donor splicing site used for the formation of the +KTS isoform Exon 9

\section{codons in the exon 9 and 10}

Figure 2. The localization of the WT1:c.1437A $>$ G substitution in the exon 9 in relation to alternative donor splice sites. Two alternative donor splice sites are marked by rectangles. The upper and lower panels show splice sites used for the formation of the -KTS and +KTS isoforms, respectively. KTS codons in the +KTS isoform are underlined by blue lines, while nucleotides corresponding to them in the - KTS isoform are underlined by grey lines. 
Further we investigated whether intron 9 is indeed retained in the patient carrying the WT1:c.1437A>G mutation. To that end, RT-PCR was performed using the patient's CDNA and primers designed to produce a PCR product exclusively if intron 9 is retained in mature mRNA (Figure S2). The RT-PCR product was cloned into a plasmid and sequenced. Sequencing confirmed the presence of intron 9 downstream of the mutated exon 9 , proving that the mutation indeed caused the intron 9 retention (Figure 3). Moreover, the intron contains a STOP codon located six nucleotides downstream of the KTS encoding triplets (Figure 3). In summary, if the erroneous mRNA is translated, the mutated allele encodes only +KTS protein lacking ZnF4 (+KTS/ - ZnF4) (Figure 4) and no -KTS isoform.

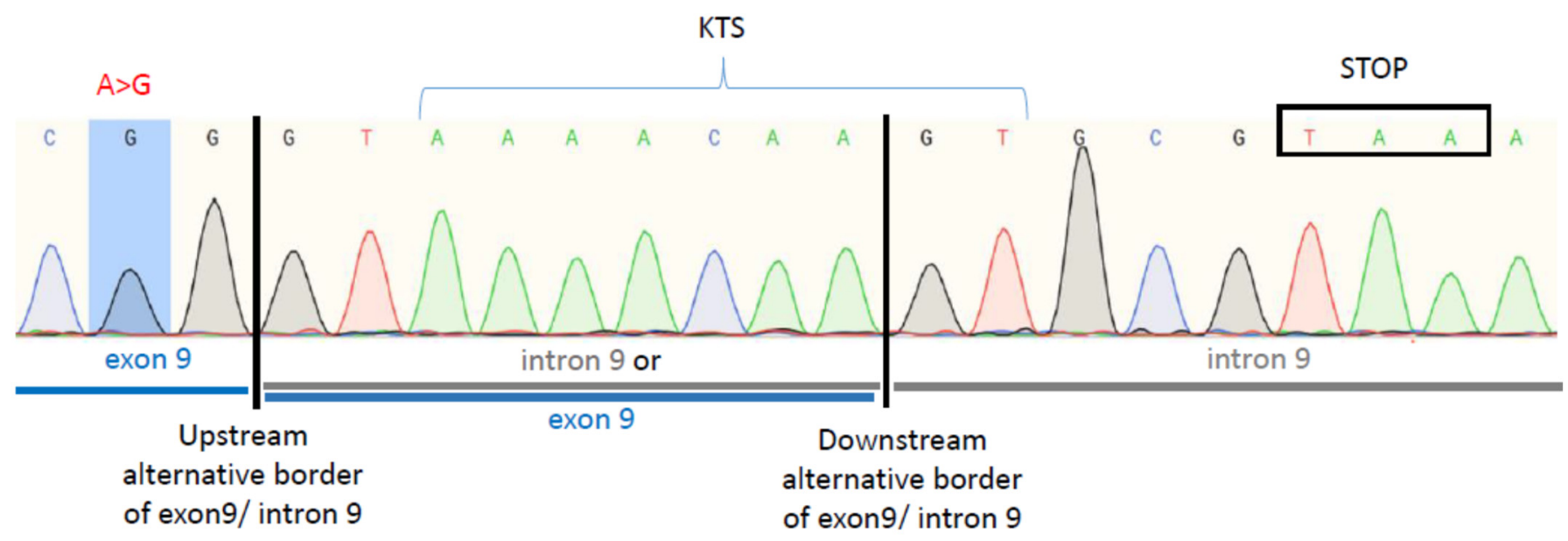

Figure 3. Confirmation of the WT1 intron 9 retention in mRNA of the 46,XX TDSD/OTDSD patient carrying the WT1:c.1437A $>$ G substitution. Sequencing of cloned RT-RCR product obtained from the cDNA of the patient shows presence of intron 9 sequence following exon 9 which contains the $A>G$ substitution in the upstream alternative donor splice site. Exon 9 is marked in blue, intron 9 is marked in gray, the sequence which belongs to exon 9 or intron 9 depending on which alternative donor splicing site is used is marked in gray and blue.

A

Normal transcript

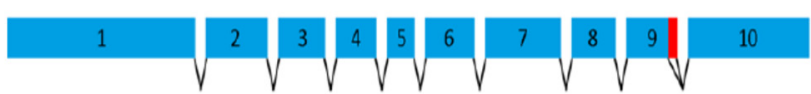

Mutant transcript
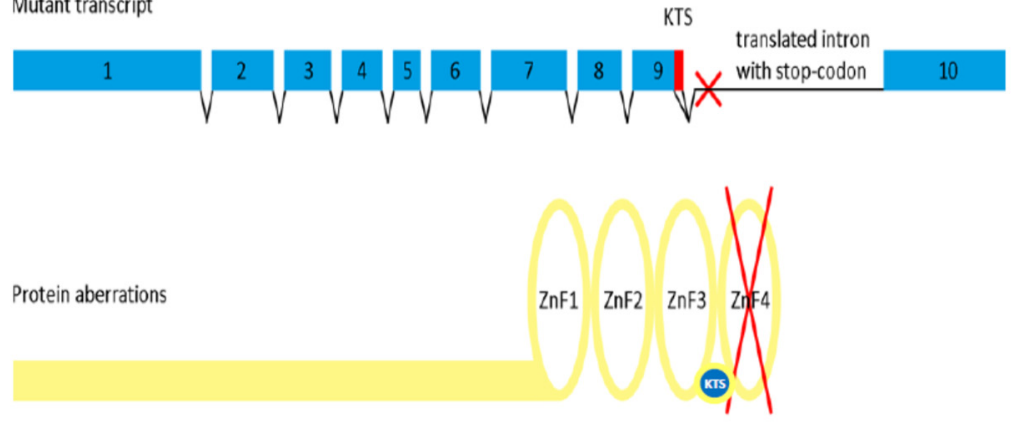

B

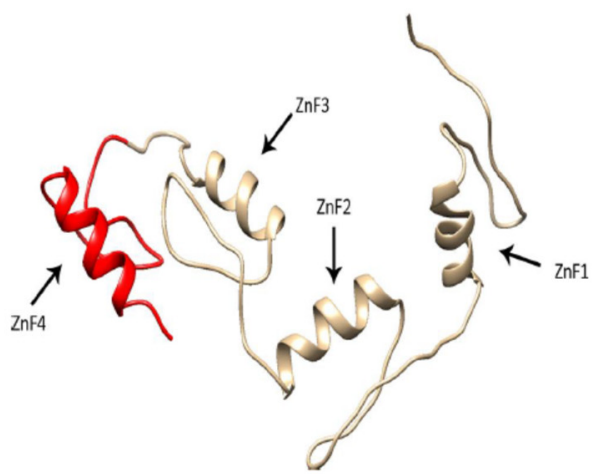

Figure 4. Aberrations of WT1 transcript and protein as a result of WT1:c.1437A>G substitution. (A) The upper panel represents a wild type WT1 alternative transcripts with KTS encoding sequence (marked with red) within the exon 9 or within the intron 9 depending on an isoform. The middle panel represents a mutated transcript containing retained intron 9 with STOP codon which is indicated as a red cross. The lower panel represents an aberrant WT1 +KTS protein lacking Zinc Finger 4 encoded by the mutated transcript (B) WT1 protein zinc fingers. Lost part of the DNA/RNA binding domain is marked with red color. 


\section{Discussion}

We discovered a WT1:c.1437A $>$ G transition in a patient with 46,XX TDSD/OTDSD. To the best of our knowledge, this variant has never been described before, nor has it been found in any large genomic screens. In an attempt to predict the level of pathogenicity for the WT1:c.1437A>G variant, we followed the standards of the American College of Medical Genetics which are commonly used to report clinically relevant variants [32]. We assigned the WT1:c.1437A>G variant status as 'pathogenic' status because it meets the criteria PVS1 (null variant in a gene where loss of function is a known mechanism of disease), PM2 (the absence in global genomic screens) and PS2 (de novo variant). Therefore we have registered WT1:c.1437A>G in the ClinVar database.

The substitution occurred at the end of exon 9, in one of two alternative donor splice sites, the upstream one. We demonstrated that the mutation causes intron 9 retention and argue that the incorrect mRNA may encode the $W T 1+K T S$ protein lacking ZnF4. Sequence of an aberrant transcript indicates that the -KTS isoform is not produced at all by the mutated allele.

Until recently, WT1 mutations were linked to 46,XY rather than 46,XX DSD. Specific pathogenic variants have earlier been found for two rare autosomal dominant diseases, Denys-Drash syndrome (MIM 194080) and Frasier syndrome (MIM 136680). These syndromes are characterized by renal anomalies and gonadal dysgenesis in 46,XY individuals, while 46,XX individuals with these syndromes typically have normal ovaries [24,33]. Denys-Drash syndrome is caused by mutations in exon 8 or 9 (encoding ZnF2 or ZnF3, respectively), believed to reduce the WT1 protein's ability concerning DNA binding [34]. In turn, Frasier syndrome is caused by mutations in the downstream alternative donor splice site within intron 9 leading to the loss of the +KTS isoform [24,25], which is required for male sex determination [23].

During the last two years, six distinct WT1 mutations have been described in 46,XX TDSD/OTDSD patients $[12,13]$ with phenotypes completely different from those associated with earlier reported WT1 mutations (46,XY gonadal dysgenesis in Denys-Drash or Frasier syndrome). Interestingly, all the 46,XX TDSD/OTDSD associated mutations affect the $\mathrm{ZnF4}[12,13]$. The mutation WT1:c.1437A $>$ G that we present here, also affecting ZnF4, is the seventh variant among those described in 46,XX TDSD/OTDSD. The WT1 mutations described so far in 46,XX TDSD/OTDSD can be classified into three groups: (1) Missense mutations in exon 10 encoding ZnF4 (p.Lys491Glu, p.Arg495Gln, p.Arg495Gly) [12]; (2) deletions at the beginning of exon 10, resulting in a frameshift, premature stop codon occurrence and predicted ZnF4 loss (p.Pro481Leufs*15, p.Arg485Glyfs*14) [12,13]; (3) substitutions within splicing sites causing (our study) or expecting retention of intron 9 and formation of only +KTS isoform lacking ZnF4: c.1437A>G (NM_024426.6; current study) and c.1448-1G>A (NM_024426.6) described as 1433-1G>A by Eozenou et al. [12]. Since all the WT1 mutations in 46,XX TDSD/OTDSD are localized within exon 10 encoding ZnF4 or within splicing sites involved in intron 9 splicing, those regions can be considered as a hot spot for $46, \mathrm{XX}$ TDSD/OTDSD causative mutations. We noticed that $\mathrm{ZnF4}$ is highly conserved from amphibian to human (Table S2) suggesting an essential role of this domain. However, the function of ZnF4 in the +KTS and -KTS isoforms was shown to be different. In the -KTS isoform, $\mathrm{ZnF} 4$ is required for DNA binding stabilization [35,36], while in $+\mathrm{KTS}, \mathrm{ZnF} 4$ is important for interaction with RNA [37].

A substantial question that should be raised here is: Which molecular mechanism(s) was (were) disturbed by WT1 mutations in 46,XY TDSD/OTDSD patients? The missense mutations (group 1) and frameshift mutations (group 2) presumably affect both + KTS and -KTS isoforms. Eozenou et al. demonstrated that point mutations p.Lys491Glu and p.Arg495Gly (same as 46,XX TDSD/OTDSD patients have), as well as one artificial mutation causing a loss of ZnF4 (p.Arg495*), enhance binding of WT1 +KTS to Catenin beta 1 [12]. Since Catenin beta 1 is known to be a pro-ovarian factor [38], these results strongly suggest that point mutations within $\mathrm{ZnF} 4$ as well as a mutation causing lack of ZnF4 (p.Arg495*) are, in fact, gain-of function mutations leading to Catenin beta 1 
sequestration, allowing for upregulation of pro-testicular pathways. Indeed, Eozenou et al. showed that WT1 p.Arg495Gly mutation upregulates SOX9, NR5A1 and DMRT1 associated with testicular Sertoli cell formation [12].

The splicing site mutations (group 3), including the one described in this work, represent a group believed to cause synthesis of truncated WT1 +KTS protein lacking ZnF4, accompanied by the absence of -KTS isoform production from the mutated allele. The WT1 truncated protein is expected to disturb formation of functional WT1 homodimers which normally act as transcriptional factor [22,39]. In the case of our patient, where both normal and mutant proteins are expected to be produced, approximately $75 \%$ of all WT1 dimers are going to be aberrant (25\% of mutant/mutant dimers, $50 \%$ of mutant/wild-type dimers, $25 \%$ of wild-type/wild-type dimers). A scenario like this drastically reduces the possibility of wild-type protein performing proper molecular functions. However the proportion of aberrant WT1 dimers may be changed if truncated WT1 protein molecules undergo inactivation by oligomerization (since formation of complexes consisting of truncated and full-length WT1 molecules was shown [40]). In each scenario, non-productive complexes (dimers or oligomers) decrease the amount of functional wild type WT1 in dominantnegative mode [40] and therefore could change WT1-regulated gene expression, including genes critical for sex development. Absence of ZnF4 in the +KTS aberrant protein may as well increase an interaction with Catenin beta 1 (like it was shown for artificial mutant lacking $\mathrm{ZnF} 4$ [13]) leading to Catenin beta 1 sequestration and prevention of its proovarian/anti-testicular function. Furthermore, because it has been established that + KTS is required for testicular determination, we propose that disruption of the +KTS/ - KTS ratio (which is predicted) may contribute to the 46,XX TDSD/OTDSD phenotype as a modifier factor in addition to loss of $\mathrm{ZnF} 4$ sequence.

\section{Materials and Methods}

\subsection{Patient Description}

A patient of Ukrainian origin (UKR29) was born after the first normal pregnancy (39 week of gestation) from a healthy 27 year old mother and 32 year old father. At birth, the child was registered as a male. Birth weight was $3500 \mathrm{~g}$ and length was $53 \mathrm{~cm}$. At the age of two months, the patient was examined due to hypospadias and bilateral cryptorchidism. At that time hormonal analysis was performed. At the age of 14 months a comprehensive examination, such as karyotyping, urological examination (including gonadal and pelvic ultrasound and MRI investigation) and hormonal analysis (including testosterone synthesis stimulation test) were performed. The patient's psychological development was normal. Neither signs of Wilms' Tumour nor renal anomalies were found in the patient.

Informed consent was obtained from the patient's parents. Ethical approval for this study was obtained from the Committee on Bioethics of the Institute of Molecular Biology and Genetics of National Academy of Sciences of Ukraine, protocol No. 2 (30 April 2013).

\subsection{Hormonal Analysis}

hCG test was performed according to a published protocol [41]. hCG (Roche Diagnostics, Germany, Mannheim) was administered at $1500 \mathrm{IU}$ for 3 days. The study of total testosterone in the blood was performed before the 1st hCG injection and $24 \mathrm{~h}$ after 3rd injection. The test is considered positive if the testosterone level is more than doubled compared to the basal level. Serum levels of free Testosterone (fT), LH, FSH and E2 were quantified by electrochemiluminescence immunoassay technology on Cobas E411 (Roche Diagnostics, Risch-Rotkreuz, Switzerland). The level of 17-OHP was quantified on Tecan SunRise (Tecan's Magellan, Männedorf, Switzerland) using commercial kit (NovaTec, Dietzenbach, Germany). Elecsys Testosterone II, Elecsys LH, Elecsys FSH and E2 kits were used according to the manufacturer's instructions (Roche Diagnostics, Germany, Mannheim). The AMH level was determined by the chemiluminescence immunoassay using paramagnetic particles by DXI 800 (Beckman Coulter, Inc., Brea, CA USA). The DHT level was determined by enzyme-linked immunosorbent assay (Demeditec, Kiel, Germany). 


\subsection{Cytogenetic Studies}

Cytogenetic studies were performed on peripheral blood lymphocytes (30 metaphase plates) using Nikon Eclipse Ci microscope (Nikon, Minato, Japan). FISH analysis was performed at 200 interphase nuclei using LUCIA Cytogenetics Software (Praha, Czech Republic) according to Cytogenetic Guidelines and Quality Assurance by European Cytogenetics Association (GTG-banding, FISH—probes CEP, LSI (Probes: Yp11.3—SRY; Yp11.1q11.1—DYZ3; Yq12—DYZ1; CEP—DXZ1) (Abbott Molecular, Libertyville, IL, USA).

\subsection{Whole Exome Sequencing (WES)}

Genomic DNA from the blood samples of the proband and his parents was isolated by using the QIAmp DNA Kit (Qiagen, Hilden, Germany). Exome capture was performed on the DNA samples using the SureSelectXT Target Enrichment system for Illumina version B.2 (Agilent Inc ${ }^{\circledR}$, Santa Clara, CA, USA). Paired-end libraries were prepared using TruSeq SBS Kit v3 (Illumina, San-Diego, CA, USA) and sequenced on an Illumina HiSeq 4000 system (Illumina, San-Diego, CA, USA). Raw sequencing was transformed into fastq files using the CASAVA v1.8.1 software (Illumina, San-Diego, CA, USA) and processed with DRAGEN Germline Pipeline v 2.3 (Edico Genome), which leverages Genome Analysis Tool Kit (GATK; https: / / gatk.broadinstitute.org/hc/en-us/articles/360045944831, last accessed 26 November 2021) and is harboured at the Illumina's cloud-based resource BaseSpace. For proband and his parents, 100 to 150 million reads were processed, adapter trimmed, duplicate marked and aligned against the GRCh37/hg19 assembly of human genome using Smith-Waterman scoring algorithm. At the variant calling stage, the following filters were applied: [Variant confidence/Quality by depth] > 2.0, [Mapping quality] $>30.0$, [Phredscaled p-value for strand bias] < 60.0, [Mapping quality RankSum] $>-12.5$, [ReadPosRankSum] $>-8.0$. Variants were annotated and analysed in Variant Interpreter (Illumina, San-Diego, CA, USA) and VarSeq (Golden Helix, Boseman, MT, USA). Further filtering was performed by the variant quality $(>500)$, genotyping quality $(>80)$, read depth $(>30)$, proportion of reads bearing the minor allele $(>0.2)$, population frequency $(<0.01)$.

\subsection{The WT1:c.1437A>G Variant Validation by Sanger Sequencing}

The variant WT1:c.1437A>G identified in the WT1 gene by WES was validated using Sanger sequencing in the patient, as compared to his parents. The fragment containing exon 9 and adjacent parts of intron 8 and 9 was amplified using the gDNA template of the patient or his parents by primers F:GACCTTCTCTGTCCATTTAG and R:CTCCTTCTCTGTATTTCCAC. PCR was done with the use of 5xHOT FIREPol ${ }^{\circledR}$ Blend Master Mix (Solis BioDyne, Tartu, Estonia) according to the manufacturer's instructions. The $286 \mathrm{bp}$ amplicon was sequenced in both directions using the above primers, in separate reactions. Sequencing was performed using BigDye ${ }^{\circledR}$ Terminator Kits (Thermo Fisher Scientific, Waltham, MA, USA) on 3130 Genetic Analyzer (Applied Biosystems, Thermo Fisher Scientific, Waltham, MA, USA). Chromatograms were analysed and converted from.ab1 format to fasta format using the open source SnapGene 4.3.11 software (GSL Biotech LLC, San-Diego, CA, USA).

\subsection{Bioinformatic Resources}

The data of the Genome Aggregation Database (gnomAD) [42], the 1000 genomes project [43], the exome sequencing project (Exome Variant Server, https: / / evs.gs.washingto n.edu/EVS/) and the Exome Aggregation Consortium (ExAC) Browser [44] were used to check the WT1:c.1437A>G variant allele frequency. Public medical genetic databases OMIM (https:/ /www.omim.org/, last accessed 26 November 2021), ClinVar (https:/ / www.ncbi.nlm.nih.gov/clinvar/, last accessed 26 November 2021) and HGVD (https: / / www.hgvd.genome.med.kyoto-u.ac.jp/, last accessed 26 November 2021) were used for the WT1:c.1437A>G variant pathogenicity evaluation. Human Splicing Finder tool [30] was used for the WT1:c.1437A>G variant impact assessment. 


\subsection{Influence of the WT1:c.1437A>G Variant on Splicing}

Total RNA was extracted from $250 \mu \mathrm{L}$ of whole blood using Tri Reagent BD (SigmaAldrich, Merck, Darmstadt, Germany) together with dsDNase pre-treatment (Thermo Fisher Scientific, USA). The amount and purity of obtained RNA were evaluated with the NanoDrop spectrophotometer (Saveen Verner, Limhamn, Sweden). cDNA was synthesized using the Maxima H Minus First Strand cDNA Synthesis Kit (Thermo Fisher Scientific, Waltham, MA, USA). Lack of gDNA in the sample was ascertained by RT-PCR using a pair of primers (F: GGACTTCGAGCAAGAGAT and R: AGCACTGTGTTGGCGTAC) complementary for an exon and a following intron of the housekeeping ACTB gene (Figure S1). Retention of WT1 intron 9 was investigated using RT-PCR with primers F:GTGTGAAACCATTCCAGTGT complementary to sequence in exon 9 and R:CCCTCTCA TCACAATTTCAT complementary to intronic 9 sequence (Figure S2). The $168 \mathrm{bp}$ amplicon was extracted and purified from agarose gel using Silica Bead DNA Gel Extraction Kit (Thermo Fisher Scientific, Waltham, MA, USA) and cloned into pJET1.2 vector (CloneJET PCR Cloning Kit, Thermo Fisher Scientific, Waltham, MA, USA). Insertion was verified by restriction analysis using $\mathrm{XhoI}$ and $\mathrm{XbaI}$ (NEB, Ipswich, MA, USA). Clones carrying correct size insert were sequenced from the pJET1.2 forward and reverse sequencing primers (Applied Biosystems 3130xl, Thermo Fisher Scientific, Waltham, MA, USA).

\subsection{Protein Modelling}

Modelling of WT1 +KTS DNA/RNA binding domain form was performed using the I-Tasser server [45] with PDB ID: 6BLW assigned as a template.

\subsection{Accession Numbers}

Accession number of Homo sapiens WT1 mRNAs is NM_024426.6. UniProt IDs of vertebrate WT1 proteins used are: Homo sapiens P19544, Sus scrofa O62651, Rattus norvegicus P49952, Mus musculus P22561, Sminthopsis macroura P49953, Gallus gallus Q9I8A0, Alligtor mississippiensis P50902, Xenopus laevis B7ZSG3, Rugosa rugosa A9CSE6.

\section{Conclusions}

A novel de novo splice site WT1 gene mutation, WT1:c.1437A>G, identified in a $46, X X$ TDSD/OTDSD patient causes retention of the intron 9. If the aberrant transcript is translated, exclusively a truncated WT1 +KTS protein lacking ZnF4 is expressed from the mutated allele. This mutation may act as a double-edge knife: (1) On the one hand, it impairs WT1 +KTS functions related to nucleic acids binding, and (2) on the other hand, it disturbs +KTS / - KTS ratio with +KTS excess, which may additionally contribute to the $46, X X$ TDSD/OTDSD phenotype as a modifier factor.

Supplementary Materials: The following are available online at https: / www.mdpi.com/article / 10.3390/biology10121248/s1, Figure S1: ACTB RT-PCR demonstrates that cDNA sample obtained from the studied patient blood is gDNA-free, Figure S2: Pair of primers used for aberrant transcript detection in cDNA of the 46,XX TDSD/OTDSD patient carrying the WT1:c.1437A>G substitution, Table S1: List of heterozygous variants in autosomal genes involved in sexual development identified in the 46,XX TDSD/OTDSD patient, Table S2: Results of multiple alignment of WT1 zinc finger 4 amino acid sequence.

Author Contributions: Conceptualization, L.L., J.J., S.N. and K.K.-Z.; Data curation, D.S., Y.V. and R.P.; Formal analysis, D.S., O.G. and N.Z.; Funding acquisition, L.L., J.J. and S.N.; Investigation, D.S., O.G., Y.V., N.Z., R.P., S.N., J.J., K.K.-Z. and L.L.; Methodology, D.S. and L.L.; Project administration, S.N., J.J. and L.L.; Resources, D.S., Y.V. and S.N.; Software, D.S., Y.V. and R.P.; Supervision, L.L., Validation, D.S., O.G., N.Z. and L.L.; Visualization, D.S.; Writing-original draft, K.K.-Z. and L.L.; Writing-review \& editing, D.S., O.G., Y.V., N.Z., R.P., S.N., J.J., K.K.-Z. and L.L. All authors have read and agreed to the published version of the manuscript. 
Funding: This research was funded by the Swiss National Science Foundation, grant number SCOPES IZ73Z0_152347/1 and National Academy of Sciences of Ukraine, project "Molecular-Genetic Mechanisms of Human Disorders of Sexual Development" [0121U110054].

Institutional Review Board Statement: The study was conducted according to the guidelines of the Declaration of Helsinki, and approved by the Committee on Bioethics of the Institute of Molecular Biology and Genetics of National Academy of Sciences of Ukraine (protocol code No.2, date of approval 30 April 2013).

Informed Consent Statement: Informed consent was obtained from the parents of the patient involved in the study.

Data Availability Statement: Data available on request due to ethical restrictions. The data presented in this study are available on request from the corresponding author.

Conflicts of Interest: The authors declare no conflict of interest.

\section{References}

1. Eggers, S.; Ohnesorg, T.; Sinclair, A. Genetic regulation of mammalian gonad development. Nat. Rev. Endocrinol. 2014, 10, 673-683. [CrossRef] [PubMed]

2. Lamothe, S.; Bernard, V.; Christin-Maitre, S. Gonad differentiation toward ovary. Ann. d'Endocrinol. 2020, 81, 83-88. [CrossRef]

3. Lee, P.A.; Nordenstrom, A.; Houk, C.P.; Ahmed, S.F.; Auchus, R.; Baratz, A.; Baratz Dalke, K.; Liao, L.M.; Lin-Su, K.; Looijenga, L.H., 3rd; et al. Global Disorders of Sex Development Update since 2006: Perceptions, Approach and Care. Horm. Res. Paediatr. 2016, 85, 158-180. [CrossRef]

4. De La Chapelle, A. Analytic review: Nature and origin of males with XX sex chromosomes. Am. J. Hum. Genet. 1972, 24, 71-105.

5. Kilberg, M.J.; McLoughlin, M.; Pyle, L.C.; Vogiatzi, M.G. Endocrine Management of Ovotesticular DSD, an Index Case and Review of the Literature. Pediatr. Endocrinol. Rev. 2019, 17, 110-116. [PubMed]

6. Croft, B.; Ohnesorg, T.; Hewitt, J.; Bowles, J.; Quinn, A.; Tan, J.; Corbin, V.; Pelosi, E.; Bergen, J.V.D.; Sreenivasan, R.; et al. Human sex reversal is caused by duplication or deletion of core enhancers upstream of SOX9. Nat. Commun. 2018, 9, 5319. [CrossRef] [PubMed]

7. Hyon, C.; Chantot-Bastaraud, S.; Harbuz, R.; Bhouri, R.; Perrot, N.; Peycelon, M.; Sibony, M.; Rojo, S.; Piguel, X.; Bilan, F.; et al. Refining the regulatory region upstream ofSOX9associated with 46,XX testicular disorders of Sex Development (DSD). Am. J. Med. Genet. Part A 2015, 167, 1851-1858. [CrossRef] [PubMed]

8. Seeherunvong, T.; Perera, E.M.; Bao, Y.; Benke, P.J.; Benigno, A.; Donahue, R.P.; Berkovitz, G.D. 46,XX sex reversal with partial duplication of chromosome arm 22q. Am. J. Med. Genet. 2004, 127A, 149-151. [CrossRef]

9. Sutton, E.; Hughes, J.; White, S.; Sekido, R.; Tan, J.; Arboleda, V.; Rogers, N.; Knower, K.; Rowley, L.; Eyre, H.; et al. Identification of SOX3 as an XX male sex reversal gene in mice and humans. J. Clin. Investig. 2011, 121, 328-341. [CrossRef]

10. Biason-Lauber, A.; Konrad, D.; Navratil, F.; Schoenle, E.J. A WNT4 mutation associated with Mullerian-duct regression and virilization in a 46,XX woman. N. Engl. J. Med. 2004, 351, 792-798. [CrossRef] [PubMed]

11. Parma, P.; Radi, O.; Vidal, V.; Chaboissier, M.-C.; Dellambra, E.; Valentini, S.; Guerra, L.; Schedl, A.; Camerino, G. R-spondin1 is essential in sex determination, skin differentiation and malignancy. Nat. Genet. 2006, 38, 1304-1309. [CrossRef] [PubMed]

12. Eozenou, C.; Gonen, N.; Touzon, M.S.; Jorgensen, A.; Yatsenko, S.A.; Fusee, L.; Kamel, A.K.; Gellen, B.; Guercio, G.; Singh, P.; et al. Testis formation in XX individuals resulting from novel pathogenic variants in Wilms' tumor 1 (WT1) gene. Proc. Natl. Acad. Sci. USA 2020, 117, 13680-13688. [CrossRef]

13. Gomes, N.L.; de Paula, L.C.; Silva, J.M.; Silva, T.E.; Lerário, A.M.; Nishi, M.Y.; Batista, R.L.; Júnior, J.A.D.F.; Moraes, D.; Costa, E.M.; et al. A 46,XX testicular disorder of sex development caused by a Wilms' tumour Factor-1 (WT1) pathogenic variant. Clin. Genet. 2019, 95, 172-176. [CrossRef] [PubMed]

14. Kreidberg, J.A.; Sariola, H.; Loring, J.M.; Maeda, M.; Pelletier, J.; Housman, D.; Jaenisch, R. WT-1 is required for early kidney development. Cell 1993, 74, 679-691. [CrossRef]

15. Kent, J.; Coriat, A.M.; Sharpe, P.; Hastie, N.D.; van Heyningen, V. The evolution of WT1 sequence and expression pattern in the vertebrates. Oncogene 1995, 11, 1781-1792.

16. Laity, J.H.; Chung, J.; Dyson, H.J.; Wright, P.E. Alternative Splicing of Wilms' Tumor Suppressor Protein Modulates DNA Binding Activity through Isoform-Specific DNA-Induced Conformational Changes. Biochemistry 2000, 39, 5341-5348. [CrossRef]

17. Ullmark, T.; Montano, G.; Gullberg, U. DNA and RNA binding by the Wilms' tumour gene 1 (WT1) protein +KTS and - KTS isoforms-from initial observations to recent global genomic analyses. Eur. J. Haematol. 2018, 100, 229-240. [CrossRef]

18. Bharathavikru, R.; Dudnakova, T.; Aitken, S.; Slight, J.; Artibani, M.; Hohenstein, P.; Tollervey, D.; Hastie, N. Transcription factor Wilms' tumor 1 regulates developmental RNAs through 3' UTR interaction. Genes Dev. 2017, 31, 347-352. [CrossRef]

19. Davies, R.C.; Calvio, C.; Bratt, E.; Larsson, S.H.; Lamond, A.I.; Hastie, N.D. WT1 interacts with the splicing factor U2AF65 in an isoform-dependent manner and can be incorporated into spliceosomes. Genes Dev. 1998, 12, 3217-3225. [CrossRef] 
20. Ullmark, T.; Järvstråt, L.; Sandén, C.; Montano, G.; Jernmark-Nilsson, H.; Lilljebjörn, H.; Lennartsson, A.; Fioretos, T.; Drott, K.; Vidovic, K.; et al. Distinct global binding patterns of the Wilms tumor gene 1 (WT1) - KTS and +KTS isoforms in leukemic cells. Haematologica 2016, 102, 336-345. [CrossRef]

21. Wang, Z.Y.; Qiu, Q.Q.; Deuel, T.F. The Wilms' tumor gene product WT1 activates or suppresses transcription through separate functional domains. J. Biol. Chem. 1993, 268, 9172-9175. [CrossRef]

22. Reddy, J.C.; Morris, J.C.; Wang, J.; English, M.A.; Haber, D.A.; Shi, Y.; Licht, J.D. WT1-mediated Transcriptional Activation Is Inhibited by Dominant Negative Mutant Proteins. J. Biol. Chem. 1995, 270, 10878-10884. [CrossRef] [PubMed]

23. Hammes, A.; Guo, J.-K.; Lutsch, G.; Leheste, J.-R.; Landrock, D.; Ziegler, U.; Gubler, M.-C.; Schedl, A. Two Splice Variants of the Wilms' Tumor 1 Gene Have Distinct Functions during Sex Determination and Nephron Formation. Cell 2001, 106, 319-329. [CrossRef]

24. Barbaux, S.; Niaudet, P.; Gubler, M.-C.; Grünfeld, J.-P.; Jaubert, F.; Kuttenn, F.; Fékété, C.N.; Souleyreau-Therville, N.; Thibaud, E.; Fellous, M.; et al. Donor splice-site mutations in WT1 are responsible for Frasier syndrome. Nat. Genet. 1997, 17, 467-470. [CrossRef] [PubMed]

25. Klamt, B.; Koziell, A.; Poulat, F.; Wieacker, P.; Scambler, P.; Berta, P.; Gessler, M. Frasier syndrome is caused by defective alternative splicing of WT1 leading to an altered ratio of WT1 +/-KTS splice isoforms. Hum. Mol. Genet. 1998, 7, 709-714. [CrossRef] [PubMed]

26. Audí, L.; Ahmed, S.F.; Krone, N.; Cools, M.; McElreavey, K.; Holterhus, P.-M.; Greenfield, A.; Bashamboo, A.; Hiort, O.; Wudy, S.A.; et al. GENETICS IN ENDOCRINOLOGY: Approaches to molecular genetic diagnosis in the management of differences/disorders of sex development (DSD): Position paper of EU COST Action BM 1303 'DSDnet'. Eur. J. Endocrinol. 2018, 179, R197-R206. [CrossRef]

27. Baxter, R.M.; Arboleda, V.; Lee, H.; Barseghyan, H.; Adam, M.P.; Fechner, P.Y.; Bargman, R.; Keegan, C.; Travers, S.; Schelley, S.; et al. Exome Sequencing for the Diagnosis of 46,XY Disorders of Sex Development. J. Clin. Endocrinol. Metab. 2015, 100, E333-E344. [CrossRef]

28. Eggers, S.; Sadedin, S.; van den Bergen, J.A.; Robevska, G.; Ohnesorg, T.; Hewitt, J.; Lambeth, L.; Bouty, A.; Knarston, I.M.; Tan, T.Y.; et al. Disorders of sex development: Insights from targeted gene sequencing of a large international patient cohort. Genome Biol. 2016, 17, 243. [CrossRef] [PubMed]

29. Fan, Y.; Zhang, X.; Wang, L.; Wang, R.; Huang, Z.; Sun, Y.; Yao, R.; Huang, X.; Ye, J.; Han, L.; et al. Diagnostic Application of Targeted Next-Generation Sequencing of 80 Genes Associated with Disorders of Sexual Development. Sci. Rep. 2017, 7, 44536. [CrossRef]

30. Desmet, F.O.; Hamroun, D.; Lalande, M.; Collod-Beroud, G.; Claustres, M.; Beroud, C. Human Splicing Finder: An online bioinformatics tool to predict splicing signals. Nucleic Acids Res. 2009, 37, e67. [CrossRef] [PubMed]

31. Diamond, R.H.; Du, K.; Lee, V.M.; Mohn, K.L.; Haber, B.A.; Tewari, D.S.; Taub, R. Novel delayed-early and highly insulin-induced growth response genes. Identification of HRS, a potential regulator of alternative pre-mRNA splicing. J. Biol. Chem. 1993, 268, 15185-15192. [CrossRef]

32. Richards, S.; Aziz, N.; Bale, S.; Bick, D.; Das, S.; Gastier-Foster, J.; Grody, W.W.; Hegde, M.; Lyon, E.; Spector, E.; et al. Standards and guidelines for the interpretation of sequence variants: A joint consensus recommendation of the American College of Medical Genetics and Genomics and the Association for Molecular Pathology. Genet. Med. 2015, 17, 405-423. [CrossRef] [PubMed]

33. Pelletier, J.; Bruening, W.; Kashtan, C.E.; Mauer, S.M.; Manivel, J.C.; Striegel, J.E.; Houghton, D.C.; Junien, C.; Habib, R.; Fouser, L. Germline mutations in the Wilms' tumor suppressor gene are associated with abnormal urogenital development in Denys-Drash syndrome. Cell 1991, 67, 437-447. [CrossRef]

34. Mueller, R.F. The Denys-Drash syndrome. J. Med. Genet. 1994, 31, 471-477. [CrossRef]

35. Nurmemmedov, E.; Yengo, R.K.; Uysal, H.; Karlsson, R.; Thunnissen, M.M. New insights into DNA-binding behavior of Wilms Tumor Protein (WT1)_A dual study. Biophys. Chem. 2009, 145, 116-125. [CrossRef]

36. Stoll, R.; Lee, B.M.; Debler, E.W.; Laity, J.H.; Wilson, I.A.; Dyson, H.J.; Wright, P.E. Structure of the Wilms tumor suppressor protein zinc finger domain bound to DNA. J. Mol. Biol. 2007, 372, 1227-1245. [CrossRef]

37. Bardeesy, N.; Pelletier, J. Overlapping RNA and DNA binding domains of the WT1 tumor suppressor gene product. Nucleic Acids Res. 1998, 26, 1784-1792. [CrossRef]

38. Chassot, A.A.; Ranc, F.; Gregoire, E.P.; Roepers-Gajadien, H.L.; Taketo, M.M.; Camerino, G.; de Rooij, D.G.; Schedl, A.; Chaboissier, M.C. Activation of beta-catenin signaling by Rspo1 controls differentiation of the mammalian ovary. Hum. Mol. Genet. 2008, 17, 1264-1277. [CrossRef]

39. Fagerlund, R.D.; Ooi, P.L.; Wilbanks, S.M. Soluble expression and purification of tumor suppressor WT1 and its zinc finger domain. Protein Expr. Purif. 2012, 85, 165-172. [CrossRef]

40. Moffett, P.; Bruening, W.; Nakagama, H.; Bardeesy, N.; Housman, D.E.; Pelletier, J. Antagonism of WT1 activity by protein self-association. Proc. Natl. Acad. Sci. USA 1995, 92, 11105-11109. [CrossRef]

41. Bertelloni, S.; Russo, G.; Baroncelli, G.I. Human Chorionic Gonadotropin Test: Old Uncertainties, New Perspectives, and Value in 46,XY Disorders of Sex Development. Sex. Dev. 2018, 12, 41-49. [CrossRef] [PubMed]

42. Karczewski, K.J.; Francioli, L.C.; Tiao, G.; Cummings, B.B.; Alfoldi, J.; Wang, Q.; Collins, R.L.; Laricchia, K.M.; Ganna, A.; Birnbaum, D.P.; et al. The mutational constraint spectrum quantified from variation in 141,456 humans. Nature 2020, 581, 434-443. [CrossRef] 
43. Auton, A.; Abecasis, G.R.; Altshuler, D.M.; Durbin, R.M.; Abecasis, G.R.; Bentley, D.R.; Chakravarti, A.; Clark, A.G.; Donnelly, P.; Eichler, E.E.; et al. A global reference for human genetic variation. Nature 2015, 526, 68-74. [PubMed]

44. Karczewski, K.J.; Weisburd, B.; Thomas, B.; Solomonson, M.; Ruderfer, D.M.; Kavanagh, D.; Hamamsy, T.; Lek, M.; Samocha, K.; Cummings, B.; et al. The ExAC browser: Displaying reference data information from over 60,000 exomes. Nucleic Acids Res. 2017, 45, D840-D845. [CrossRef] [PubMed]

45. Yang, J.; Zhang, Y. I-TASSER server: New development for protein structure and function predictions. Nucleic Acids Res. 2015, 43, W174-W181. [CrossRef] 